\title{
Planning Horizon as a Key Element of a Competitive Strategy
}

\author{
Letycja Sołoducho-Pelc
}

\begin{abstract}
The paper presents existing research results concerning the importance of the long horizon as a key element of competitive strategy. Results of research carried out on a sample of 150 companies were presented, with special focus on those that create precise plans for an over 5-year-long time horizon. Strategic management areas such as strategy formalization, level of strategy expensiveness, competition strategy, organization of work on strategy, familiarity with the strategy and tasks were submitted to detailed analysis. The research helped identify a relation between a clear definition of future vision and the necessity to formalize the strategy; dynamic growth as a strategic priority and having significant competitive advantage; launching products into new market segments, expanding product portfolio and increasing competitive edge; organizing and planning work on strategy and making executive pay dependent upon realization of strategic goals; all employee's familiarity with the strategy as well as the possibility to clearly allocate all tasks to particular departments in the process of creating and implementing the strategy.
\end{abstract}

Index Terms-Planning horizon, strategy, competitive strategy, strategic management.

\section{INTRODUCTION}

The feature of the contemporary world is permanent insecurity, changeability or even chaos. In such a situation the temptation not to plan and limit all activities to reacting to changes is growing stronger. Opposite activities, i.e. planning the future, seem hard or even impossible to implement in practice. Strategic analysis can include various methods of investigating future trends and events in the environment, nevertheless in case of each organization decision are made on the basis of limited knowledge about the future.

Contemporary knowledge and management methods do not offer alternative solutions, compared to conscious long-term development of a company's future perspectives despite, or even in contrary to, turbulent changes in the environment. Despite difficulties related to comparing future events, the only correct development path seems to be strong orientation to the future, which means that we make decisions on our future actions today.

It can be assumed that taking actions related to conscious formation of one's own future is a decisive factor for survival, development and victory in competitive struggle. The point is, achieving each of these aims requires preparation and implementation of a long-term strategy. One of the most

Manuscript received September 5, 2013; revised November 62013.

Letycja Sołoducho-Pelc is with the Wrocław University of Economics, Poland (e-mail: letycja.soloducho@gmail.com). significant difficulties in developing efficient, victorious strategies, is the necessity to combine two contradictions, which make up a kind of a strategic paradox: the need to implement the planned strategy and the need to introduce changes.

This article elaborates on discussions and analysis related to the impact of long-term (more than five years) time horizon on the competitive strategy implemented by the company and taking the leadership position ${ }^{1}$.

\section{TIME HORIZON OF A STRATEGY - LITERATURE OVERVIEW}

Due to changes, which take place in the environment and inside the strategist's organization, the time horizon dimension factor is especially criticized. The subject literature even suggests the dusk of the strategy - the 'attack' of insecurity on strategy is mentioned, alongside the impossibility to implement the strategy in practice in our times [1], [2].

The strategy can be defined as a rational decision making process, rather evolutionary than revolutionary, under which a company specifies, which aims it wants to achieve and in what way it wants to realize its vision of development on a competitive market [3]. A strategy is used to 'transfer' an organization from the current state to the planned state, therefore it has to be adjusted to the current and future situation of an organization [4]. Therefore it is very significant to identify untypical changes, which are carriers of new chances and risk at the same time [5]. Environmental changes are so unpredictable that decisions made under a strategy has to be based on future scenarios, whose development requires long-term planning [6].

The strategy formulation process and executive actions undertaken as part of implementation require various schedules. Therefore plans developed for the purpose of strategy performance are short, medium and long-term. Performing each of them requires knowledge and skills of various people, preparation of timetables, and can bring different results. Consistency of short- and medium-term actions with long-term actions is necessary. If actions are conducted correctly, then the need to correct strategies is rare, enforced by untypical external and internal changes.

The duration of long-term strategies depends first of all on the potential of a company and the stability and character of changes which create chances and threats in the environment. One of the most frequently made mistakes is shortening the time horizon below 5 years. In this way an organization

\footnotetext{
${ }^{1}$ The project was financed with the funds of the National Science Centre as a research project no. N N115402240.
} 
performs tactical actions, which do not develop the company potential, and hence do not build competitive advantage based on innovation [7]. Although forecasting distant future has limited applications, and a strategy is featured by uncertainty of information about the future, focusing attention on planning allows to identify potential developmental opportunities, and also recognize risks [8]. Shortening a time horizon is related to significant negative consequences concerning growth, development or competitiveness of an organization [9].

Taking into account the selection of the length of the time horizon, research results pointing at the significance of developing long-term plans to achieve high organizational efficiency, are very important [10]. Currently the form of the strategy matters less, and the greatest pressure is put on the 'doing strategy [11]. However, the formalization of the strategy still matters; its demonstration is designing a strategy in the form of a formal document employees are familiarized with - such organizations grow two times faster [12].

The point of reference for all actions related to the strategy is vision and strategic objectives, whose performance has to be specified within concrete time frames. Developing long-term visions and planning their implementation allows to [13]:

1) Define timeless aspirations of a company and design a strategy, which allow a vision to be fulfilled.

2) Prepare a developmental plan of developing a competitive potential of an organization, which will allow building competitive advantage and will be a response to competitive macro-changes.

Strategic objectives define the future target position of the organization, and the strategy outlines the way and time of their achievement [14]. The selection of strategic objectives helps to identify resources necessary to develop in the long run, and apart from that it is also a motivating factor for the management and employees. The time horizon is tightly related to the strategic objectives, because all decisions concerning the strategic objectives refer to the given time horizon. It refers to such time frames, within which the strategic objectives are achieved by performing the outlined tasks.

The time horizon serves as a future frame-border, whose dimension is time. The time horizon indicated in the strategy becomes a durable future border. Many advantages related to the selection of a long-term time horizon of a strategy can be enumerated:

- Initiating strategic thinking about the future of the organization and constant search for new developmental perspectives;

- Focusing by the leaders on being visionaries and exploiting the intellectual capital of an organization;

- Guaranteeing that the decisions taken currently will be consistent with the long-term goals;

- Maintaining balance between the current resources and the necessary future potential;

- Minimizing uncertainty and preparing for inevitable changes.

Making the time horizon precise requires not only realism and imagination of people in charge of the strategy, but also possessing a lot of information and the ability to interpret them [15]-[16]. In Table I determiners of the time horizon selection were presented.

TABLE I: DETERMINERS OF THE TIME HORIZON SELECTION

\begin{tabular}{|c|l|l|}
\hline Kind of factors & \multicolumn{1}{|c|}{ Key question } & $\begin{array}{l}\text { Factors determining the } \\
\text { time horizon selection }\end{array}$ \\
\hline $\begin{array}{c}\text { Organizational } \\
\text { factors }\end{array}$ & $\begin{array}{l}\text { Until which } \\
\text { future moment do } \\
\text { we need to plan? }\end{array}$ & $\begin{array}{l}\text { - Time necessary to fulfill } \\
\text { strategic objectives (lead } \\
\text { time) } \\
\text { - Product life cycle } \\
\text { - Organization life cycle } \\
\text { - Changes in technology } \\
\text { - Validity of planning } \\
\text { premises } \\
\text { - Present value }\end{array}$ \\
\hline factors & $\begin{array}{l}\text { Until which } \\
\text { future moment } \\
\text { are we able to } \\
\text { plan? }\end{array}$ & $\begin{array}{l}\text { Cognitive limitations } \\
\text { (reality and rationality of } \\
\text { perception of uncertainty } \\
\text { related to the future) }\end{array}$ \\
& & $\begin{array}{l}\text { Risk acceptance } \\
\text { - Time and financial } \\
\text { limitations } \\
\text { - Information limitations }\end{array}$ \\
\hline
\end{tabular}

Source: Own work based on: [17]

When determining the correct time horizon, it is important to know the specificity of a company and operation sector, resulting from the knowledge and experience of strategists-leaders.

The range of the time horizon is enormous, from planning 12 months ahead, to focusing attention on the next 20 years [18]. Currently shortening of the time horizon of strategies can be observed, from 10-15 years to $3-5$ years, which is a response to the unpredictability of changes occurring in the environment. The most popular time horizon reaches 5 years ahead, however, such a length of the horizon does not constitute a standard for planning. Setting a long time horizon - i.e. more than 5 years - enforces the implementation of decisions related to the strategy, on condition that necessary changes are introduced, resulting from changes in the environment and the organization [19].

The meaning of a long horizon is related to the perception of the organization from a new perspective, the opportunity to generate and test innovative ideas, the ability to build competitive potential. On the other hand, shortening the time horizon is meaningful in terms of tactical or implementation actions.

The issue of making the length of the time horizon of the strategy more precise in a changeable, unordered environment, still arouses some interest. Therefore a new term appeared in the literature of the subject - horizon scanning (HS) related to environmental scanning (ES). The aim of HS is systematic scanning of the environment in order to investigate potential opportunities, trends, threats and risks from the perspective of the future developmental opportunities [20], [21]. Also in war games - a scientific tool used to study the strategy of competitors - special emphasis is put on five dimensions: the market, competitors, functional areas, time horizon, scenarios [22]. Time horizon was found to be the factor of special meaning concerning the building of 
competitive potential, because it allows to acquire information about future trends and events faster than the competitors [23].

The time factor, called time compression, has become an important determiner of competitive advantage, because it enhances productivity, increases quality, speeds up innovation commercialization [24]. Companies, which gained advantage over their competitors, have a flexible approach to the strategic process, because only in this way they can react to changes in the global competitive environment. However, even a prompt reaction is insufficient, because it is necessary to gain advantage over competitors by means of strategic far-sightedness. Companies winning in the competitive fight stretch the strategy process among four correlating dimensions: the time horizon, vision, strategic thinking and engagement process. Strong orientation to the future means that today we decide what actions we will take in the future, which is how we move from the 'now' perspective to the 'then' perspective.

\section{RESEARCH MeTHOdOLOGY}

Below results of a study conducted on the sample of 150 Polish companies are presented. All subjects embraced by the study were joint stock companies, listed at the Warsaw Stock Exchange (WSE) and the New Connect market $(50,7 \%)$ and not listed at the WSE $(49,3 \%)$. Considering the criterion of size, the sample included 50 large entities (more than 250 employees), 50 medium-size (from 50 to 250 employees) and 50 small enterprises (fewer than 50 employees). The first criterion pre-qualifying to the study was the establishment of the company between 1989 - 2009. The second criterion was the requirement that the company had to be established based on the Polish capital. Due to the research topic, all respondents were individuals holding the highest managerial positions in the companies.

The study focused on the strategic management practice in companies. The Paper and Pencil Interview technique was used, and all interviews were conducted by a research agency. The interview questionnaire included 4 questions in the recruitment part, 11 questions in the personal information part and 84 questions in the main part. The questions in the main part referred to four areas: the strategic management process, strategic management participants, strategy forms and strategy content. The respondents referred to the statements included in subsequent questions, selecting their responses on the Likert scale.

\section{RESEARCH RESULTS}

Below results of the research on the length of the time horizon and its impact on the competitive strategy were presented. The study sought answers to the following research question: Does long-term planning the company development helps to sustain and allows to take the leadership position? In order to answer this question, answers to question 19 were focused on: 'Long-term (more than 5 years) plans of our company are scrupulously specified'. 71 companies were selected from among all companies taking part in the study. These were the subjects, which answered positively to the above question, i.e. indicated 'definitely yes' and 'rather yes' on the scale. To verify the positive impact of a long time horizon on the competitive strategy, 9 hypotheses were formulated, which were later presented in Table II.

\begin{tabular}{|c|c|c|}
\hline Area & Hypothesis & $\begin{array}{l}\text { Question no. } \\
\text { in the } \\
\text { questionnaire }\end{array}$ \\
\hline $\begin{array}{c}\text { Strategy } \\
\text { formalization }\end{array}$ & $\begin{array}{l}\text { H1: Clearly defined vision of the } \\
\text { future is related to formalization } \\
\text { of a strategy. }\end{array}$ & 5 and 3 \\
\hline $\begin{array}{c}\text { Strategy } \\
\text { expansiveness } \\
\text { level }\end{array}$ & $\begin{array}{l}\mathrm{H} 2 \text { : There is a relation between } \\
\text { dynamic growth as a strategic } \\
\text { priority, and having substantial } \\
\text { advantage over competitors. }\end{array}$ & $\begin{array}{c}22 \text { and M2. } \\
\text { (dynamic and } \\
\text { moderate growth) }\end{array}$ \\
\hline \multirow{3}{*}{$\begin{array}{c}\text { Competitive } \\
\text { strategy }\end{array}$} & $\begin{array}{l}\text { H3: Introducing products to new } \\
\text { market segments and broadening } \\
\text { the product portfolio strengthens } \\
\text { the advantage over competitors. }\end{array}$ & 28 and 29 and 30 \\
\hline & $\begin{array}{l}\text { H4: There is a relation between } \\
\text { constant search for new operation } \\
\text { areas (market, product) and } \\
\text { building competitive advantage in } \\
\text { the field of innovation and } \\
\text { technology. }\end{array}$ & 26 and 34 \\
\hline & 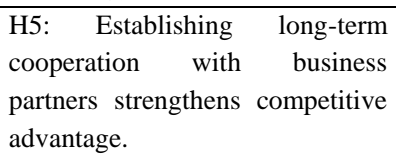 & 39 and 30 \\
\hline $\begin{array}{l}\text { Organization } \\
\text { of works on a } \\
\text { strategy }\end{array}$ & $\begin{array}{l}\text { H6: Organizing and planning } \\
\text { works on a strategy allows to } \\
\text { depend company management } \\
\text { remuneration on the achievement } \\
\text { of strategic objectives. }\end{array}$ & 43 and 61 \\
\hline $\begin{array}{l}\text { Knowledge of } \\
\text { a strategy } \\
\text { and } \\
\text { distribution } \\
\text { of tasks }\end{array}$ & $\begin{array}{l}\text { H7: Knowledge of a strategy by } \\
\text { all employees creates an } \\
\text { opportunity to define tasks for } \\
\text { different departments clearly } \\
\text { under the process of strategy } \\
\text { development and implementation. }\end{array}$ & 73 and 78 \\
\hline
\end{tabular}

Source: Own work

TABLE III: TAU KENDALL CORRELATION

\begin{tabular}{|c|c|c|}
\hline Hypothesis & Questions & $\begin{array}{c}\text { Tau - b Kendall } \\
\text { correlation coefficient }\end{array}$ \\
\hline H1 & q5 vs. q3 & $0.339^{* *}$ \\
\hline H2 & $\begin{array}{c}\text { q22 vs. revenue } \\
\text { dynamics 2009-2011 }\end{array}$ & $-0.369^{* *}$ \\
\hline H3 & q28 vs. q29 & $0.420^{* *}$ \\
\hline H3 & q28 vs. q30 & $0.217^{*}$ \\
\hline H3 & q29 vs. q30 & $0.289^{* *}$ \\
\hline H4 & q26 vs. q34 & 0.149 \\
\hline H5 & q39 vs. q30 & 0.095 \\
\hline H6 & q43 vs. q61 & $0.227 *$ \\
\hline H7 & q73 vs. q78 & $0.494 *$ \\
\hline
\end{tabular}

* Correlation significant at the 0.05 level (bilateral)

** Correlation significant at the 0.01 level (bilateral) Source: Own work 
TABLE IV: DESCRIPTIVE STATISTICS

\begin{tabular}{|c|c|c|c|c|c|c|c|c|c|c|c|c|c|}
\hline \multirow{4}{*}{ 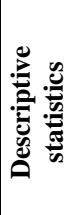 } & Standard deviation & 1.5 & 1.2 & 1.0 & 1.2 & 1.3 & 1.0 & 1.4 & 0.8 & 1.3 & 1.2 & 1.2 & 1.2 \\
\hline & Dominant & 2 & 4 & 5 & 5 & 5 & 4 & 5 & 5 & 5 & 5 & 4 & 4 \\
\hline & Median & 3 & 4 & 4 & 4 & 4 & 4 & 4 & 5 & 3 & 4 & 4 & 4 \\
\hline & Average & 2.9 & 3.8 & 4.2 & 3.7 & 3.8 & 3.3 & 3.5 & 4.5 & 3.4 & 3.9 & 3.7 & 3.9 \\
\hline \multirow{6}{*}{ 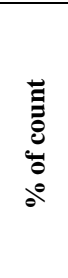 } & Definitely yes & $21 \%$ & $34 \%$ & $49 \%$ & $35 \%$ & $41 \%$ & $6 \%$ & $31 \%$ & $56 \%$ & $25 \%$ & $37 \%$ & $30 \%$ & $34 \%$ \\
\hline & Rather yes & $17 \%$ & $37 \%$ & $35 \%$ & $27 \%$ & $23 \%$ & $45 \%$ & $27 \%$ & $35 \%$ & $23 \%$ & $32 \%$ & $37 \%$ & $34 \%$ \\
\hline & Yes and no & $14 \%$ & $13 \%$ & $7 \%$ & $18 \%$ & $21 \%$ & $27 \%$ & $15 \%$ & $3 \%$ & $21 \%$ & $10 \%$ & $11 \%$ & $17 \%$ \\
\hline & Rather not & $25 \%$ & $10 \%$ & $7 \%$ & $15 \%$ & $8 \%$ & $13 \%$ & $14 \%$ & $1 \%$ & $24 \%$ & $14 \%$ & $15 \%$ & $7 \%$ \\
\hline & Definitely not & $21 \%$ & $7 \%$ & $1 \%$ & $4 \%$ & $7 \%$ & $7 \%$ & $11 \%$ & $1 \%$ & $7 \%$ & $4 \%$ & $6 \%$ & $6 \%$ \\
\hline & I don't know & $1 \%$ & $0 \%$ & $0 \%$ & $0 \%$ & $0 \%$ & $3 \%$ & $1 \%$ & $3 \%$ & $0 \%$ & $3 \%$ & $1 \%$ & $3 \%$ \\
\hline \multirow{8}{*}{$\vec{\Xi}$} & Total & 71 & 71 & 71 & 71 & 71 & 71 & 71 & 71 & 71 & 71 & 71 & 71 \\
\hline & Definitely yes & 15 & 24 & 35 & 25 & 29 & 4 & 22 & 40 & 18 & 26 & 21 & 24 \\
\hline & Rather yes & 12 & 26 & 25 & 19 & 16 & 32 & 19 & 25 & 16 & 23 & 26 & 24 \\
\hline & Yes and no & 10 & 9 & 5 & 13 & 15 & 19 & 11 & 2 & 15 & 7 & 8 & 12 \\
\hline & Rather not & 18 & 7 & 5 & 11 & 6 & 9 & 10 & 1 & 17 & 10 & 11 & 5 \\
\hline & Definitely not & 15 & 5 & 1 & 3 & 5 & 5 & 8 & 1 & 5 & 3 & 4 & 4 \\
\hline & I don't know & 1 & 0 & 0 & 0 & 0 & 2 & 1 & 2 & 0 & 2 & 1 & 2 \\
\hline & Question & $q 3$ & $q 5$ & $q 26$ & $q 28$ & $q 29$ & $q 30$ & $q 34$ & $q 39$ & $q 43$ & $q 61$ & $q 73$ & $q 78$ \\
\hline
\end{tabular}

In order to verify the hypotheses, correlation was calculated bases on the tau-b Kendall correlation coefficient. It is a non-parametric measure of rank correlation. Since all questions in the questionnaire were based on an ordinal scale ${ }^{2}$, using this correlation was justified. Correlations were calculated using the tau-b Kendall method presented in Table III.

From among seven research hypotheses, two hypotheses (H4 and H5) are not statistically significant. Based on the obtained results, it is not possible to draw generalization conclusions concerning the assumptions made for the whole population. Considering hypothesis $\mathrm{H} 4$, conclusions can only be drawn for companies taking part in the study.

Hypothesis 1 indicated the relation between a clear vision of the future and the necessity to formalize a strategy. The obtained correlation coefficient can be assessed as average, which means that there is a positive relation between the enhanced precision of the visions of future and the increase in the strategy formality. Therefore it indicates that it is important to transform a vision, which is the factor determining the development of the strategy, into e.g. a document. It can be stated that if an organization has a precise vision of the future, then it specifies its strategy to a greater extent in the form of e.g. a document - and the other way round, too. The implementation of the strategic management concept means that it is necessary to link different elements of the strategy, such as vision and strategy form, because they are interrelated.

The obtained negative correlation result allowed the verification of hypothesis 2 . In this case there is a weak ${ }^{3}$ and average ${ }^{4}$ correlation between the strategic priority, i.e. dynamic growth, and having a substantial advantage over competitors. It means that an increase in the meaning of the strategic priority. i.e. dynamic growth, is related to a decrease

\footnotetext{
${ }^{2}$ It is possible to rank questions according to their size, it is not possible to indicate quantitative differences among questions.

${ }^{3}$ Average revenue dynamics in 2009.

${ }^{4}$ Average revenue dynamics in 2010, 2011 and 2009-2011.
}

in the substantial competitive advantage, and the other way round - the greater the competitive advantage, the smaller the meaning of the strategic priority, defined as dynamic growth. This relation is quite interesting, since in the literature in the subject and empirical research there is an assumption that organizations should not only develop, but grow following a strategy of moving from a small, through medium to a large organization, because this is one of the key elements of building a strong competitive advantage on the globalized market.

Hypothesis 3 concerned the relation between introducing products to new market segments and broadening the product portfolio, and strengthening the competitive advantage. The obtained result indicates the existence of an average positive correlation between launching products on new market segments and broadening the product portfolio. The more products are introduced to new market segments, the broader the product portfolio becomes. Meanwhile, weak positive correlations were observed between: introducing products to new market segments and strengthening the competitive advantage, and broadening the product portfolio and strengthening the competitive advantage. Therefore, the correlation between the number of products introduced to new market segments and the greater competitive advantage was verified positively. Meanwhile, the broader the product portfolio, the greater the competitive advantage. Therefore it can be assumed that the innovation of an organization, demonstrated by launching products on new market segments and broadening the product portfolio, is related to the strengthening of competitive advantage. In addition, both launching new products, and broadening the product portfolio, correlate positively with each other.

A weak positive correlation was observed between questions included in hypothesis 6 . The relation between organizing and planning works on the strategy, and depending the company management remuneration on the achievement of strategic goals, was confirmed. It means that the more organized and planned works on the strategy are, 
the greater the dependence of the company management remuneration on the achievement of strategic goals is. Such a relation exists in case of organization, which put great emphasis both on developing the strategy concept, and its implementation, and treat both activities as parts of the same process.

Hypothesis 7 indicated relations between the knowledge of the strategy by all company employees, and the possibility to define activities of different departments clearly, under the process of developing and implementing the strategy. The obtained correlation result can be interpreted as average. It means that the greater the knowledge of the strategy among the company employees, the greater the possibility to clearly define tasks of different departments under the process of developing and implementing the strategy. Hence putting emphasis on communicating the strategy to organization employees, a precise division of tasks and increasing the employee awareness of their role in the strategic management process, are interrelated.

In Table IV the most important conclusions drawn from the descriptive statistics were presented, calculated for subsequent questions being the subject of the analysis.

Below a short comment on descriptive statistics was presented. The study results refer to such enterprises, which specify long-term (more than 5 years) company plans.

The first questions required referring to the statement that the company strategy is an extensive formal document (question 3). $38 \%$ of the studied companies responded positively, while $46 \%$ of the companies denied having their strategy in the form of an extensive formal document.

The issue of having a clearly defined vision was investigated in the following question (question 5). Most companies $-71 \%$ - confirmed the existence of a clearly defined vision, while $17 \%$ of companies declared not having a clearly defined vision.

The following question (question 26) had the purpose of obtaining information about constant search or new operation areas (market, product). As many as $84 \%$ of companies confirmed undertaking this kind of activity, with only $8 \%$ claiming they do not undertake such actions.

The next question concerned the priority, which is introducing products to new market segments (question 28). Most companies - 63\% - confirmed that they considered introducing products to new market segments as a priority. $19 \%$ of the companies do not treat this kind of activities as their priority.

The matter of considering the broadening of product portfolio as a priority was investigated by the following question (question 29). 64\% of the companies responded positively, while $15 \%$ of them claimed they did not treat broadening of product portfolio as a priority.

Having a substantial advantage over competitors was the subject of question 30 in the questionnaire. 51\% of the companies confirmed they had a leading position, compared to their competitors, while $20 \%$ of them did not assess their competitive advantage as significant.

The next question referred to the statement that the basic competitive advantage of a company is based on innovations and technology (question 34). 54\% of the studied companies responded positively, while $25 \%$ denied such sources of the basic competitive advantage.

The significance of a long-term cooperation with business partners was the subject of question 39 in the questionnaire. $91 \%$ of companies admitted that it was important to establish a long-term cooperation with business partners. Only $2 \%$ did not consider that kind of cooperation as significant.

The next question had the purpose of assessing works on the strategy in terms of organization and planning (question 43 ). $48 \%$ of the studied companies confirmed that their work on the strategy is organized and planned. $31 \%$ of them denied their work on the strategy had such nature.

Then the dependence of the company management remuneration on the achievement of strategic objectives was investigated (question 61). 69\% of the studied companies confirmed that the remuneration of their management board depended on the achievement of strategic goals. $28 \%$ of them denied the existence of such a relation between the remuneration of the management board and the achievement of strategic objectives.

The next question referred to the issue of putting large emphasis on familiarizing all company employees with the company strategy (question 73). 67\% of the studied companies responded positively, while $21 \%$ of them denied ascribing great importance to familiarizing all company employees with the strategy.

The last question referred to the fact that different company departments have clearly defined tasks under the process of strategy development and implementation (question 78). 68\% of the studied companies specified tasks of different departments clearly, hence facilitating the strategic management process. Meanwhile $13 \%$ of the companies did not undertake such actions.

\section{CONCLUSION}

Even in the times features by fierce competition and crisis, none has doubts that long-term planning is the key to success, no matter if one thinks about their child's development or plans their own professional career. However, faced with quick, barely predictable changes, organizations make a decision to shorten the time horizon of a strategy. Strategic activities are replaced with operation activities, being active and creative are substituted by reacting passively to the occurring changes.

In order to verify the ideas concerning long-term planning, it was assumed to be the key element of the competitive strategy, which allows sustaining and taking the leadership position. In addition, most of the studied enterprises, which specify long-term (more than 5 years) company plans:

- Do not have a strategy in the form of an extensive document.

- Have clearly specified vision.

- Search constantly for new operation areas (market, product).

- Treat the introduction of products to new market segments and broadening of the product portfolio as a priority.

- Have acquired a competitive advantage. 
- $\quad$ Base the company competitive advantage on innovation and technology.

- $\quad$ Put emphasis on long-term cooperation with business partners.

- $\quad$ Organize and plan works on the company strategy.

- Make the company management remuneration dependent on the achievement of strategic objectives.

- $\quad$ Put great emphasis on the knowledge of the company strategy by all employees.

Analyzing the study results, it is worth noticing the existence of relations between:

- Clear specification of the vision of the future, and the need to formalize the strategy.

- Dynamic growth as a strategic priority, and having substantial competitive advantage.

- Introducing products to new market segments and broadening the product portfolio, and enhancing the competitive advantage.

- Organizing and planning works on the company strategy, and conditioning the company management remuneration on the achievement of strategic objectives. Knowledge of the strategy by all employees, and the possibility to define tasks of different departments clearly, under the process of the strategy development and implementation.

There is no need to convince anyone that the strategy is a source of immense benefits, but can also lead to failure, e.g. due to the lack of planning of the future. The strategy by its 'nature' creates values for an organization in the long run. Success is a derivative of planning in the long run, too. In this case it is important to have a clear vision of the future, organizing and formalizing both works on the strategy, and the strategy itself, setting brave aims, putting strong procedural emphasis on achieving strategic objectives, defining employee tasks clearly under the strategic process. It can be assumed that - to handle the paradox of long-term planning in changeable environment - it is necessary to implement the strategy, and meanwhile manage the changes in the long-term perspective (time horizon). The awareness that the current decisions are futuristic by their nature and they are the most important decisions from the perspective of the company's present time and future, should help to look ahead.

\section{REFERENCES}

[1] A. Rylander and J. Peppard, "From implementing strategy to embodying strategy," Journal of Intellectual Capital, vol. 4, no. 3, pp. $318,2003$.

[2] S. French, "Critiquing the language of strategic management," Journal of Management Development, vol. 28, no. 1, pp. 6, 2009.

[3] K. C. Feurer, "Strategy development: Past, present and future," Training for Quality, vol. 5, no. 2, pp. 58, 1997.

[4] A. Bordum, "The strategic balance in a change management perspective," Society and Business Review, vol. 5, no. 3, pp. 245, 2010.
[5] B. Leavy, "Managing the risks that go with high-impact strategies in uncertain markets," Strategy and Leadership, vol. 35, no. 4, pp. 44-45, 2007.

[6] G. Getz, C. Jones, and P. Loewe, "Migration management: An approach for improving strategy implementation," Strategy and Leadership, vol. 37, no. 6, pp. 23, 2009.

[7] S. Mezger and M. Violani, "Seven basic strategic missteps and how to avoid them," Strategy and Leadership, vol. 39, no. 6, pp. 22, 2001.

[8] F. J. Lin, "The development of planning horizon theory and the comparison of decision/forecast horizons for dynamic lot size models," Journal of Modeling in Management, vol. 2, no.2, pp. 170, 2007.

[9] S. Mitchelmore and J. Rowely, "Growth and planning strategies within women-led SMEs," Management Decision, vol. 51, no. 1-2, pp. 83-85, 2013.

[10] S. Kraus, R. Harms, and E. J. Schwarz, "Strategic planning in smaller enterprises-new empirical findings," Management Research News, vol. 29, no. 6, pp. 336, 2006.

[11] J. Pugh and L. J. Bourgeois, "Doing strategy," Journal of Strategy Management, vol. 4, no. 2, pp. 172, 2011

[12] S. Kraus, R. Harms, and E. J. Schwarz, "Strategic planning in smaller enterprises-new empirical findings," Management Research News, vol. 29 , no. 6, pp. 336, 2006

[13] "Stretching the strategy process," Strategic Direction, vol. 25, no. 1, pp. 17, 2009.

[14] G. Getz and J. Lee, "Why your strategy isn't working," Business Strategy Series, vol. 12, no.6, pp. 305, 2011.

[15] J. Radomska, "Readiness of the organisation to engage employees in the strategy creation and implementation process," Journal of International Scientific Publication, Economy \& Business, vol. 6, pp. 221-230, 2012.

[16] L. S. Pelc and J. Radomska, "The role of human capital in creating competitive advantage based on technology," in Proc. International Conference on ICT Management for Global Competitiveness and Economic Growth in Emerging Economies, Wroclaw, Poland, 2012, pp. 161-182.

[17] E. F. Harrison, "Strategic planning maturities," Management.

[18] M. Chussil, "Learning faster than competition: war games give the advantage," Journal of Business Strategy, vol. 28, no. 1, pp. 40-41, 2007.

[19] S. Abraham and B. Leavy, "After 15 editions, the authors of strategic management textbook reflect," Strategy and Leadership, vol. 35, no. 4, 2007.

[20] I. Miles and O. Saritas, "The depth of the horizon: searching, scanning and widening horizons," Foresight, vol. 14, no. 6, pp. 530, 2012.

[21] M. A. Palomino, S. Bardsley, K. Bown, J. D. Lurio, P. Ellwood, D. H. Smith, B. Huggins, A. Vincenti, H. Woodroof, and R. Owen, "Web-based horizon scanning: concepts and practice," foresight, vol. 14, no. 5, pp. 355, 2012.

[22] M. Chussil, "Learning faster than competition: war games give the advantage," Journal of Business Strategy, vol. 28, no. 1, pp. 40-41, 2007.

[23] C. M. Connell, "Pursuing three horizons of growth-three cases: Bomabardier (Canada), Disney (US) and Hutchison Whampoa (China)," Business Strategy Series, vol. 8, no.1, pp. 15, 2007.

[24] L. T. Hui, "Business timeliness: The intersections of strategy and operations management," International Journal of Operations \& Production Management, vol. 24, no. 6, pp. 605, 2004.

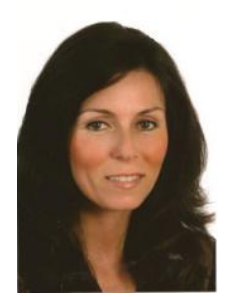

Letycja Soloducho-Pelc is a Ph.D. She was born in Wroclaw, Poland. In 2005 she awarded the academic degree of Doctor at Wroclaw University of Economics. Her $\mathrm{PhD}$ thesis was connected with the topic of Strategic management in small enterprises. She works as an assistant professor at Wroclaw University of Economics, in Strategic Management Department. Her research interests are connected with strategic management process, strategic management in SME, successful strategies, female entrepreneurship. 